УДК 340.15(470.65)

DOI dx.doi.org/10.24866/1813-3274/2020-1/90-102

\begin{abstract}
А. М. Цалиев ${ }^{1}$, Северо-Кавказский горно-металлургический институт (государственный технологический университет), г. Владикавказ, Россия E-mail: kafedra-pd@skgmi-gtu.ru
\end{abstract}

\title{
АКТУ АЛЬНЫЕ ПРОБЛЕМЫ РЕГИОНАЛЬНОЙ ПРАВОВОЙ СИСТЕМЫ (НА ПРИМЕРЕ РЕСПУБЛИКИ СЕВЕРНАЯ ОСЕТИЯ - АЛАНИЯ)
}

Аннотащия. В статье анализируются и раскрываются источники региональной правовой системы. Наряду с основными и текущими законами субъектов Российской Федерации, в числе источников региональной правовой системы признаются те договора и соглашения, которые не противоречат Конституции Российской Федерации. Правовое регулирование вопросов, за решение которых несут ответственность Российская Федерация и образующие её субъекты, осуществляется в особом правовом режиме. Активизация договорной практики между органами государственной власти Российской Федерации и её субъектами на основе принципа субсидиарности, рассматриваемая в работе, будет способствовать развитию федеративных отношений, формированию федеративного государства, национальной и региональной правовых систем, более эффективному решению социально-экономических и иных задач.

В число источников региональной правовой системы предлагается включить нормы неписаного права. Рассматривается их значение в регулировании общественных отношений. Эти суждения более всего касаются национальных республик, где в регуляции социального поведения всё ещё важное место занимают нормы традиционного общества - обычаи, традиции, составляющие основу неписаной Конституции и отражающие представления о добре и зле, справедливости и несправедливости. Они же способствуют преемственности поколений в передаче правовых ценностей, правовых знаний, умений, навыков и правового опыта. Поэтому весьма важно учитывать их в правотворческой и правоприменительной деятельности.

\footnotetext{
${ }^{1}$ Александр Михайлович Цалиев, зав. кафедрой конституционного и административного права юридического факультета Северо-Кавказского горно-металлургического института (государственного технологического университета) - СКГМИ (ГТУ), доктор юридических наук, профессор, заслуженный юрист РФ, г. Владикавказ, Россия.

Для цитирования: Цалиев А. М. Актуальные проблемы региональной правовой системы (на примере Республики Северная Осетия - Алания) // Азиатско-Тихоокеанский регион: экономика, политика и право. 2020. № 1. С. 90-102.
}

(C) Цалиев А. М., 2020 
Цалиев А. М. Актуальные проблемы региональной правовой системы (на примере Республики Северная Осетия - Алания)

Автор приходит к выводу, что в Конституцию РСО - Алания необходимо включить отдельную статью с наименованием «Правовая система Республики Северная Осетия - Алания». Её содержание сформулировать следующим образом: 1. Республика Северная Осетия - Алания имеет свою правовую систему. 2. Источниками правовой системы Республики Северная Осетия - Алания являются: Конституция; законы; нормативно-правовые акты; общепризнанные принципы и нормы международного права; международные соглашения Республики Северная Oceтия - Алания; договоры и соглашения РСО - Алания с федеральными органами государственной власти, а также субъектами РФ; осетинские обычаи.

Ключевые слова: Конституция Российской Федерации; Конституция Республики Северная Осетия - Алания; международное законодательство; региональная правовая система; договор и соглашение; нормы обычного права.
Alexander M. Tsaliev ${ }^{1}$, North Caucasian State Medical University (GTU), Vladikavkaz, Russia
E-mail: kafedra-pd@skgmi-gtu.ru

\section{ACTUAL PROBLEMS OF THE REGIONAL LEGAL SYSTEM (CASE STUDY OF THE REPUBLIC OF NORTH OSSETIA - ALANIA)}

Abstract. The sources of regional legal system have been analyzed and disclosed in the article. Along with the basic and current laws of the subjects of the Russian Federation, the sources of the regional legal system include treaties and agreements to the extent that they are international, those that do not contradict the Constitution of the Russian Federation. Legal regulation of issues which the Russian Federation and its constituent entities are responsible for is carried out in a special legal regime. The intensification of contractual practice between the state authorities of the Russian Federation and its constituent entities on the basis of the principle of subsidiarity, which is considered in the work, shall contribute to the development of federative relations, to the formation of a federative state, national and regional legal systems, to a more effective solution of socioeconomic and other problems.

It is proposed to include the norms of unwritten law among the sources of the regional legal system. Their significance in regulating social relations has been considered. These judgments mostly concern the national republics where the norms of the traditional society customs, traditions that constitute the basis of the unwritten Constitution and reflect the no-

\footnotetext{
${ }^{1}$ Alexander M. Tsaliev, Head Department of Constitutional and Administrative Law, Faculty of Law, North Caucasian Mining and Metallurgical Institute (State Technological University) - SKGMI (GTU), Doctor of Law., Professor, Honored Lawyer of the Russian Federation, Vladikavkaz, Russia.

For citing: Tsaliev A. M. Actual problems of the regional legal system (case study of the Republic of North Ossetia - Alania) // PACIFIC RIM: Economics, Politics, Law. 2020. No 1. P. 90-102.
} 
tions of good and evil, justice and injustice - still occupy an important place in the regulation of social behavior. They also contribute to the continuity of generations in the transmission of legal values, legal knowledge, skills and legal experience. It is therefore very important to take them into account in the law-making and law enforcement.

The author concludes that the Constitution of North Ossetia-Alania should include a separate article titled "Legal System of the Republic of North Ossetia-Alania". Its content should be formulated as follows: 1. The Republic of North Ossetia-Alania has its own legal system. 2. 2. The sources of the legal system of the Republic of North OssetiaAlania are the Republic of North Ossetia-Alania: Constitution; laws; normative and legal acts; generally accepted principles and norms of international law; international agreements of the Republic of North Ossetia-Alania; treaties and agreements of North OssetiaAlania with federal bodies of state power as well as with constituent entities of the Russian Federation; Ossetian customs.

Keywords: Constitution of the Russian Federation; Constitution of the Republic of North Ossetia-Alania; international legislation; regional legal system; treaty and agreement; norms of customary law.

Строительство правового федеративного государства предполагает повышение социальной роли права, закона, развития федеративных отношений, в том числе в формировании правовой системы. Она в постсоветский период формируется не только на федеральном, но и на региональном уровнях как следствие расширения полномочий субъектов Российской Федерации в сфере законодательства. Так, согласно ч. 2 ст. 5 действующей Конституции Российской Федерации, в отличие от предыдущей Конституции Российской Федерации, субъекты Российской Федерации имеют не только свою конституцию (устав), но и законодательство - законы и иные нормативные правовые акты. Кроме того, согласно ч. 4 ст. 76 Конституции РФ «Вне пределов ведения Российской Федерации, совместного ведения Российской Федерации и субъектов Российской Федерации республики, края, области, города федерального значения, автономная область и автономные округа осуществляют собственное правовое регулирование, включая принятие законов и иных нормативных правовых актов». В случае противоречия между федеральным законом и нормативным правовым актом субъекта Российской Федерации, изданным по предметам его исключительного ведения, действует нормативный правовой акт субъекта Российской Федерации. Такое правовое регулирование, включая право на опережающее законодательство, осуществляется субъектом Российской Федерации по принципу собственного усмотрения и социальной необходимости, исходя из сложившихся обычаев и традиций, условий жизнедеятельность народа. 
Правовое регулирование вопросов, за решение которых несут ответственность Российская Федерация и образующие её субъекты, осуществляется в особом правовом режиме. Конституционный Суд РФ, рассмотрев эту проблему, указал, что выработка правовых норм здесь должна строиться на основе достижения баланса интересов Российской Федерации и её субъектов, взаимоуважения и взаимной ответственности с обязательным использованием согласительных процедур [1]. По данному вопросу следует иметь в виду решение Конституционного Суда РФ, согласно которому до принятия федеральных законов по вопросам, отнесённым к предметам совместного ведения, субъекты Федерации вправе осуществлять по таким вопросам собственное правовое регулирование. После принятия соответствующего федерального закона законы и иные нормативные правовые акты субъектов Федерации приводятся в соответствие с принятым федеральным законом. Отсутствие федерального закона в сфере совместного ведения не может служить препятствием для субъекта Федерации издавать собственный закон или иной нормативный правовой акт [3]. Такой подход к правовому регулированию предметов совместного ведения Российской Федерации и её субъектов, в том числе по совместным отраслям законодательства, является вполне логичным, поскольку позволяет, во-первых, оперативно решать назревшие вопросы законодательного регулирования тех вопросов, которые нуждаются в этом, во-вторых, обеспечить режим единой законности в Российской Федерации.

Указанные федеральные конституционные положения и решения Конституционного Суда РФ активно используют субъекты Российской Федерации, что позволяет формировать достаточно полноценное региональное законодательство, ставшее одним из важнейших источников региональной правовой системы. К их числу относятся также общепризнанные принципы и нормы международного права, международные договоры, заключённые Российской Федерацией как от своего имени, так и от имени её субъектов. В этом выражается единство внешней и внутренней политики, проводимой Российской Федерацией и её субъектами [7, с. 58]. Вместе с тем, как отметил Президент России В. В. Путин в своем Послании на 2020 г., «требования международного законодательства и договоров, а также решения международного законодательства и договоров, а также решения международных органов могут действовать на территории России только в той части, в которой они не влекут за собой ограничения прав и свобод человека и гражданина, не противоречат нашей Конституции». На мой взгляд, данное предложение необходимо дополнить, указав в конце его конституционные законы, являющиеся одним из главных источников конституционного права и принимаемые по вопросам, предусмотренным конституцией. Нормы такого закона не могут по своему правовому статусу иметь меньшую юридическую силу, чем нормы международного законодательства.

Отметим, что положение ч. 4 ст. 15 Конституции РФ воспроизводится во многих основных законах субъектов Российской Федерации в части признания об- 
щепризнанных принципов и норм международного права, международных соглашений источниками региональной правовой системы. Так, ч. 4 ст. 14 Конституции Республики Северная Осетия - Алания предусматривает, что «Общепризнанные принципы и нормы международного права, международные соглашения Республики Северная Осетия - Алания, заключённые в соответствии с федеральным законодательством, являются составной частью правовой системы Республики Северная Осетия - Алания».

В числе источников региональной правовой системы следует предусмотреть также договоры и соглашения между субъектами Российской Федерации и федеральными органами государственной власти, между субъектами Российской Федерации. Подчеркнём, что договорная практика между различными органами государственной власти начала активно складываться после подписания Федеративного договора 1992 г. Как участник разработки проекта данного документа свидетельствую, что одной из важнейших его целей было максимально полно учесть особенности субъектов Российской Федерации при разработке и подписании договоров между региональными и федеральными органами государственной власти. Однако в процессе договорной практики некоторые субъекты РФ получили необоснованно завышенные полномочия, особенно после известного ельцинского лозунга «Берите столько суверенитета, сколько сможете проглотить». Такая порочная государственная политика и практика в строительстве федеративного государства привела к тому, что договор, будучи правовой формой решения государственных вопросов, сначала использовался неумело, а то и деструктивно. Поэтому после начавшегося процесса укрепления российской государственности договорная практика была вообще свёрнута и начался процесс сверхцентрализации государственной власти. Таким образом, в строительстве своей новой государственности Россия в очередной раз приняла крайнее решение.

Анализируя данный процесс, В. А. Черепанов, проработавший заместителем Полномочного представителя Президента РФ в разных республиках Северного Кавказа, пришёл к выводу, что в условиях сверхцентрализации государственной власти и «молчаливого недовольства» по этому поводу региональных органов власти назрела насущная необходимость в заключении нового Федеративного договора, который сформулирует и закрепит общее согласие Федерации и образующих её субъектов по основам федеративного устройства Российского государства [10, с. 328]. Конституция РФ предполагает такую правовую форму разрешения и совершенствования федеративных отношений. Так, согласно ч. 3 ст. 11 Конституции РФ «разграничение предметов ведения и полномочий между органами государственной власти Российской Федерации и органами государственной власти субъектов Российской Федерации осуществляется настоящей Конституцией, Федеративным и иными договорами о разграничении предметов ведения и полномочий». В свою очередь отметим, что ак- 
тивизация договорной практики между органами государственной власти Российской Федерации и её субъектами на основе принципа субсидиарности будет способствовать развитию федеративных отношений, формированию федеративного государства, национальной и региональной правовых систем, более эффективному решению социально-экономических и иных задач.

Особое место среди источников в региональной правовой системе занимают соглашения между субъектами Российской Федерации и иностранными государствами. Правовой основой данного процесса являются, во-первых, федеральный закон от 15 июля 1995 г. «О международных договорах Российской Федерации», предусматривающий участие субъектов Российской Федерации в сфере внешней политики; во-вторых, федеральный закон от 6 октября 1999 г. «Об общих принципах организации законодательных (представительных) и исполнительных органов государственной власти субъектов Российской Федерации» (п. 47 ч. 2 ст. 26.3), которым установлено, что к полномочиям органов государственной власти субъектов Российской Федерации по предметам совместного ведения относятся решения вопросов осуществления международного сотрудничества в соответствии с законодательством Российской Федерации, в том числе, «приграничного сотрудничества, участия в осуществлении государственной политики в отношении соотечественников за рубежом»; в-третьих, конституции (уставы) субъектов Российской Федерации. Так, в ст. 16 Конституции РСО - Алания предусматривается, что «Республика Северная Осетия - Алания строит свои отношения с Республикой Южная Осетия в соответствии с федеральным законодательством на основе этнического, национального, историко-территориального единства, социально-экономической и культурной интеграции». На основе данной региональной конституционной нормы заключены многие соглашения между Республикой Северная Осетия - Алания и Государством Южная Осетия - Алания.

К числу источников региональной правовой системы следует отнести нормы обычного права, которые играют важную роль в регулировании общественных отношений у народов, сохранивших в значительной мере традиционный образ жизни. Как правильно отмечает Н. Н. Разумович, «хотим мы этого или нет, обычное право действует. Оно существует и будет существовать столько, сколько просуществует право, оказывая влияние на правовое развитие, восполняя пробелы в зонах правового общения, а также там, где законопредписания нежизнеспособны» [8, с. 25]. Ещё во времена римских юристов существовало правило: «В тех делах, в которых мы не пользуемся писаными законами, нужно соблюдать то, что указано нравами и обычаями».

По мере развития государства обычное право постепенно уступает дорогу закону. Тем не менее, оно продолжает иметь место среди источников права, особенно региональных. В некоторых субъектах России, в основном входящих в Северо- 
Кавказский федеральный округ, можно наблюдать взаимодействие норм российского законодательства, обычного права, а также норм религии [11, с. 155]. Интерес к обычному праву возникает особенно при радикальных реформах законодательства, права, правовой системы, как это имеет место в постсоветский период. Это обусловлено тем, что вновь возникшие общественные отношения не могут быть в полной мере урегулированы действующим законодательством, а новое ещё не разработано. В таком правовом вакууме среди источников правовой системы заметно усиливается социальная роль норм обычного права народов. Если говорить об Осетии, применительно к двум её республикам, то составной частью их правовых систем должны быть предусмотрены осетинские обычаи как нормы неписаного права. Они возникли значительно раньше норм писаного права. Их место и роль были незаменимы в жизни осетинского общества. Об этом писали академики В. Б. Пфафф, М. М. Ковалевский и многие другие известные учёные. Специалисты считают, что обычаям «следовали не потому, что сила традиций подавляла человека, ей подчинялись потому, что она была внутренне вплетена в огромную живую сеть взаимоотношений, устроенную дотошно организованным образом» [см.: 9, с. 98].

Социальная значимость норм обычного права была столь велика, что без строгого их соблюдения нельзя было поддерживать правопорядок в обществе, решать вопросы жизнедеятельности членов общества, обеспечивать их безопасность. Несмотря на сказанное, в истории Осетии не раз предпринимались административные меры по их искоренению.

Так, ещё в середине XIX в. известный осетинский генерал М. Кундухов, воспитанный на идеях Просвещения, резко выступал против части народных обычаев и традиций. Вступая в должность начальника военно-осетинского округа (населённого не только осетинами), он провозгласил программу преобразований на основе «развития всякой гражданственности и благоустройства в народе». В ряде институтов народной жизни он видел «нелепость и зло», находя их «не соответствующими духу настоящего времени», «обременительными и разоряющими домашнее благосостояние». М. Кундухов заявил горцам о своём намерении вывести их из нищеты и «поставить в состояние цивилизованных народов».

Отменяя одни адаты и существенно изменяя другие, он стремился регламентировать горскую жизнь до «мелочей», вплоть до подробных указаний - что и сколько может быть съедено и выпито на поминках, как вести себя жёнам на похоронах мужей, какие памятники ставить на могилах, каким святым поклоняться, сколько человек приглашать на свадьбу и т.д.

М. Кундухов полагал, что для успешного утверждения нового порядка достаточно строгого его исполнения, с широким применением административных мер, в частности штрафов, по отношению к нарушителям. Круто ломая привычный уклад народной жизни, он, конечно, руководствовался самыми благими побуждениями и 
Цалиев А. М. Актуальные проблемы региональной правовой системы (на примере Республики Северная Осетия - Алания)

ещё не мог знать о том, что другой «радикал-реформатор» Шамиль, заимствовавший восточные образцы государственности, уже после пленения признает грубой ошибкой своё стремление одним ударом покончить с «вредными» привычками горцев, вместо того чтобы предоставить это времени и естественному ходу вещей [см.: 3, с. 238].

Попытки искоренить административными мерами, на взгляд чиновников, вредные обычаи и традиции неоднократно предпринимались и в советский период. Так, в первые годы Советской власти стали упразднять нормы шариата и шариатское судопроизводство, которое к тому времени имело более чем двухсотлетнюю историю существования. Это привело к тому, что в начале 1918 г. в Кабарде муллы приняли энергичные меры к захвату власти и настояли на том, чтобы восстановили шариатское судопроизводство. Новая власть трезво оценила политическую ситуацию, и поэтому 4 марта 1918 г. на II съезде народов Терской области его делегаты приняли резолюцию: «Каждому народу предоставляется право организовать свои народные суды, творящие правосудие согласно народным обычаям и нравам».

Приведённые и аналогичные многочисленные исторические примеры в судьбе одного народа, руководствовавшегося столетиями в своей жизни нормами обычного права - адатами (ирон æгъдау), вызывают закономерный интерес к тому, насколько эти неписаные нормы ныне соблюдаются и присутствуют в действующей Конституции РСО - Алания, если не в буквальном смысле, то хотя бы сохранившими их дух. К сожалению, их практически невозможно обнаружить даже при очень внимательном прочтении конституционных норм. На мой взгляд, это стало следствием безудержной, бездумной и ничем не аргументированной критики норм обычного права, хотя именно благодаря им народ, и не только осетинский, столетиями и даже тысячелетиями смог сохранить себя и свою национальную самобытность. Это важно понять ныне, когда в жизни всё большее место занимают материальные ценности, а к обычаям и традициям нередко начали проявлять меркантильный интерес. В такое время долг национальной элиты - предпринимать соответствующие усилия по их сохранению, раскрытию их роли и значения в жизнедеятельности народа, утверждению их статуса не только в национальном самосознании, но и в нормативных документах.

Следует помнить, что попытки запретить, подавить традицию, которые, как правило, предпринимаются в ходе включения традиционных обществ в широкое этнокультурное, экономическое, социальное, правовое пространство могут, как отмечает профессор 3. В. Канукова, привести только к нивелированию активных и многообразных, чаще всего визуальных форм бытования традиции. Развиваясь в течение многих веков, традиция приобретает безупречный механизм адаптации в изменяющихся объективных условиях, в значительной степени основанный на сочетании консервативности со способностью к постоянному обновлению. 
Анализ исторического опыта народов Северного Кавказа показывает, что в ходе включения в российское административное, правовое социокультурное и хозяйственное пространство традиционные культуры проявили жизнеспособность, основанную на глубинных уровнях этнического мироощущения и сознания [5, с. 5]. Не случайно профессор Д. Ю. Шапсугов отмечает: «...новая эпоха не отменяет принципа органичности правового развития, носителем которого выступало право традиционного общества» $[12$, с. 12]. Более того, в литературе правильно отмечается, что общество обречено на полный коллапс социально-нормативной системы, если новые институты коллективности не смогут совместиться с традиционными, что успехов в модернизации добились именно те регионы, в которых гражданское общество и демократические ценности сохранились в форме культурных традиций [6, с. 258].

Мировая этнологическая наука пришла к выводу, что обычаи представляют собой отлаженную веками систему организации жизнедеятельности и самосохранения общества, механизма приспособления к окружающей среде (рельеф, климат, поведение соседних народов и т.д.). Вобрав опыт многих поколений, они (обычаи) упорядочили человеческие отношения, прекратили состояние «войны всех против всех», способствовали достижению социального равновесия, политической стабильности, этнической целостности. Обычаи, будучи ещё и средством формирования народного самосознания, помогли людям обрести собственное лицо. В этой, так сказать, «самоидентификации» заложена мощная духовная и психологическая энергия, прочная нравственная опора, позволяющая этносу ощутить в себе то, что С. М. Соловьев назвал «природой племени». Огромная информация об этой «природе» закодирована именно в обычаях.

В связи со сказанным сошлёмся на слова Председателя Конституционного Суда РФ В. Д. Зорькина о том, что «мы должны серьёзно, ответственно и бережно учитывать и использовать сохранившиеся в российской социальной ткани неписаные нормы здоровой массовой моральной регуляции. Делать это должны хотя бы потому, что только они, по большому счёту, реально восполняют всё ещё недостаточную эффективность законодательного правового регулирования» [4, с. 2].

Эти суждения более всего касаются национальных республик, где в регуляции социального поведения всё ещё важное место занимают нормы традиционного общества - обычаи, традиции, составляющие основу неписаной Конституции и отражающие представления о добре и зле, справедливости и несправедливости. Они же способствуют преемственности поколений в передаче правовых ценностей, правовых знаний, умений, навыков и правового опыта. Поэтому весьма важно учитывать их в правотворческой и правоприменительной деятельности. Так, исторический опыт традиционного медиаторства может быть использован в разработке миротворческих методик при создании проектов, направленных на внедрение традиционных элементов урегулирования споров и криминальных ситуаций в деятель- 
ность официальной юстиции, в образовательные курсы по восстановительному правосудию [см.: 5, с. 101].

К социальной значимости их в настоящее время всё чаще обращаются, поскольку без них невозможно в полной мере урегулировать все общественные отношения. В предыдущие столетия они вообще регулировались исключительно нормами обычного права, которое, по общему признанию наиболее известных учёных, было весьма развито в Осетии. Народ всегда противился попыткам власти игнорировать национальные обычаи и традиции, ставшие основой их социальной жизни и регулирующие различные общественные отношения.

Следует согласиться с Д. Ю. Шапсуговым в том, что у прогрессивных обычаев и традиций есть не только прошлое, но и настоящее и будущее [16, с. 632]. Не случайно в Конституции Карачаево-Черкесии устанавливается, что «Общепризнанные прогрессивные обычаи и традиции народа республики: уважение к старшему, женщине, людям различных религиозных убеждений, милосердие - священны». Такие обычаи и традиции существуют и в других национальных республиках, поэтому их законодателям есть над чем призадуматься. На мой взгляд, следует найти возможность предусмотреть соответствующую норму и в конституциях других республик. В них следует закрепить также норму об институте примирения как древнем обычае разрешение конфликта, который и поныне действует у многих народов. Так, в Осетии стороны конфликта, их родственники часто прибегают к примирительным процедурам. Этот социально значимый обычай особую ценность приобретает у народов с большим распространением кровнородственных связей, поскольку в конфликт бывает втянуто большое количество людей. Наряду со сказанным нельзя тешить себя надеждой, что одним лишь законодательным закреплением даже самых хороших обычаев и традиций мы решим проблему. Необходима реальная практическая работа по данному вопросу.

Рассуждая о социальной значимости национальных обычаев и традиций и оценивая их социальную значимость, стоит прислушаться к мнению Председателя Конституционного Суда России В. Д. Зорькина, который считает, что неписаные нормы «составляют корневую основу государственно-правовой системы». Отметим также, что в системе источников российского права обычаи занимают заметное место. Так, в Гражданском кодексе РФ (ст. 5) законодательно закрепляется факт признания их в качестве источников права, расширяются возможности применения по сравнению с ранее действовавшим законодательством. Об этом свидетельствует Постановление Пленума Верховного суда от 31 мая 2015 г. «О Применении судами некоторых положений раздела I ч. 1 Гражданского Кодекса Российской Федерации». Согласно постановлению, суды при разрешении споров в сфере гражданского права могут применять обычай не только в сфере предпринимательства, но и в другой деятельности. Можно привести ещё и другие примеры, свидетельствующие о 
распространении норм обычного права как социальных регуляторов. Не случайно на международном уровне, в отличие от российского права, признается существование и действие обычного права. Его изучение у разных народов способствует более глубокому учёту национально-региональной специфики в правотворчестве и правоприменении.

С учётом изложенного, в порядке правовой инициативы, предлагаю в Конституцию РСО - Алания включить отдельную статью с наименованием «Правовая система Республики Северная Осетия - Алания». Её содержание сформулировать следующим образом: 1. Республика Северная Осетия - Алания имеет свою правовую систему. 2. Источниками правовой системы Республики Северная Осетия Алания являются: Конституция; законы; нормативно-правовые акты; общепризнанные принципы и нормы международного права; международные соглашения Республики Северная Осетия - Алания; договоры и соглашения РСО - Алания с федеральными органами государственной власти, а также субъектами РФ; осетинские обычаи.

\section{Список литературы}

1. По делу о проверке конституционности ряда положений Устава - Ocновного Закона Читинской области : Постановление Конституционного Суда РФ от 01 февраля 1996 г. № 3-П. - URL: https://legalacts.ru/doc/postanovleniekonstitutsionnogo-suda-rf-ot-01021996-n/ (дата обращения: 11.02.2010).

2. По делу о проверке конституционности Указа Президента Российской Федерации от 15 августа 1992 г. «Об организации управления электроэнергетическим комплексом Российской Федерации в условиях приватизации» : Постановление Конституционного Суда РФ от 10 сентября 1993 г. № 15-П. - URL: https://legalacts.ru/doc/postanovlenie-konstitutsionnogo-suda-rf-ot-10091993-n/ (дата обращения: 11.02.2010).

3. Дегоев, В. Большая игра на Кавказе: история и современность. - 2-е изд., расшир. и доп. - Москва : Русская панорама, 2003. - 510 с.

4. Зорькин, В. Д. Проблемы конституционно-правового развития (к 20летию Конституции РФ) // Журнал конституционного правосудия. - 2014. - № 2. C. $1-9$.

5. Канукова, 3. В. Традиции в современном осетинском обществе / 3. В. Канукова. - Владикавказ : Ир, 2018. - 135 с.

6. Патнэм, Р. Чтобы демократия работала: Гражданские традиции в современной Италии / Р. Патнэм. - Москва : Ad Marginem, 1997. - 286 с.

7. Переплеснина, Е. Н. Общепризнанные принципы и нормы международного права, международные договоры РФ в российской правовой системе / Е. Н. Переплеснина. - Петрозаводск, 2009. - 192 с. 
8. Разумович, Н. Н. Источники права и форма права // Советское государство и право. - 1988. - № 3. - С. 20-27.

9. Свечникова, Л. Г. Понятие и обычаи современной науки: подходы, традиции, проблемы (на материалах юридической и этнологической наук) // Государство и право. - 1998. - № 9. - С. 98-102.

10. Черепанов, В. А. Проблемы российской государственности. Опыт системного исследования / В. А. Черепанов. - Москва : НОРМА ; ИНФРА-М, 2018. - 336 с.

11. Шапиев, Р. Н. Соотношение обычного права и законодательства // Проблемы в российском законодательстве. - 2017. - № 2. - С. 155-157.

12. Шапсугов, Д. Ю. Теоретико-правовые основания исследований правового мира Кавказа // Правовой мир Кавказа: прошлое, настоящее, будущее : материалы международной научно-практической конференции, 14-15 апреля 2011 г. Нальчик, 2011. - С. 12.

13. Шапсугов, Д. Ю. Проблемы теории и истории власти, права и государства / Д. Ю. Шапсугов. - Москва : Юрист, 2003. - 685 с.

\section{References}

1. In the case of the constitutionality of a number of provisions of the Charter - the Basic Law of the Chita Region: Resolution of the Constitutional Court of the Russian Federation of February 1, 1996 No. 3-P. Available at: https://legalacts.ru/doc/post anovleniekonstitutsionnogo-suda-rf-ot-01021996-n/ (accessed 11 February 2010). (In Russian).

2. In the case of the constitutionality review of the Decree of the President of the Russian Federation of August 15, 1992 "On the organization of management of the electric power complex of the Russian Federation in the context of privatization»: Resolution of the Constitutional Court of the Russian Federation of September 10, 1993 No. 15-P. Available at: https://legalacts.ru/doc/postanovlenie-konstitutsionnogo-suda-rf-ot10091993-n/ (accessed: 11 February2010).

3. Degoev V. Bol'shaya igra na Kavkaze: istoriya $i$ sovremennost' [The big game in the Caucasus: history and modernity]. 2nd ed., expand. and add. Moscow: Russkaya panorama Publ., 2003. 510 p.

4. Zorkin V. D. Problemy konstitutsionno-pravovogo razvitiya (k 20-letiyu Konstitutsii RF) [Problems of constitutional legal development (on the 20th anniversary of the Constitution of the Russian Federation)]. Zhurnal konstitutsionnogo pravosudiya, 2014, no. 2, pp. 1-9.

5. Kanukova Z. V. Traditsii v sovremennom osetinskom obshchestve [Traditions in modern Ossetian society]. Vladikavkaz: Ir Publ., 2018. 135 p.

6. Putnam R. Chtoby demokratiya rabotala: Grazhdanskie traditsii v sovremennoi Italii [For democracy to work: Civil traditions in modern Italy]. Moscow: Ad Marginem Publ., 1997. 286 p. 
7. Pereplesnina E. N. Obshchepriznannye printsipy i normy mezhdunarodnogo prava, mezhdunarodnye dogovory $R F v$ rossiiskoi pravovoi sisteme [The generally recognized principles and norms of international law, international treaties of the Russian $\mathrm{Fe}$ deration in the Russian legal system]. Petrozavodsk, 2009. 192 p.

8. Razumovich N. N. Istochniki prava i forma prava [Sources of law and the form of law]. Sovetskoe gosudarstvo i pravo, 1988, no. 3, pp. 20-27.

9. Svechnikova L. G. Ponyatie i obychai sovremennoi nauki: podkhody, traditsii, problemy (na materialakh yuridicheskoi i etnologicheskoi nauk) [The concept and customs of modern science: approaches, traditions, problems (based on the materials of legal and ethnological sciences)]. Gosudarstvo i pravo, 1998, no. 9, pp. 98-102.

10. Cherepanov V. A. Problemy rossiiskoi gosudarstvennosti. Opyt sistemnogo issledovaniya [Problems of Russian statehood. Experience in systems research]. Moscow: NORMA; INFRA-M Publ., 2018. 336 p.

11. Shapiev R. N. Sootnoshenie obychnogo prava i zakonodatel'stva [Correlation of customary law and legislation]. Problemy v rossiiskom zakonodatel'stve, 2017, no. 2, pp. $155-157$.

12. Shapsugov D. Yu. Teoretiko-pravovye osnovaniya issledovanii pravovogo mira Kavkaza [Theoretical and legal foundations of studies of the legal world of the Caucasus]. In: Pravovoi mir Kavkaza: proshloe, nastoyashchee, budushchee: materialy mezhdunarodnoi nauchno-prakticheskoi konferentsii, 14-15 aprelya 2011 g. [Legal world of the Caucasus: past, present, future: proceedings of an international scientific and practical conference, April 14-15, 2011]. Nalchik, 2011, pp. 12.

13. Shapsugov D. Yu. Problemy teorii $i$ istorii vlasti, prava i gosudarstva [Problems of the theory and history of power, law and the state]. Moscow: Yurist Publ., 2003. $685 \mathrm{p}$. 